\title{
Rheumatoid arthritis in 2003: where are we now with treatment?
}

\section{E Weinblatt}

T he treatment of rheumatoid arthritis (RA) has changed considerably over the course of the century. It is difficult to fathom that 100 years ago it was directed towards removing potential sources of infection, with dental extractions and tonsillectomies. Despite appreciable advances, many of the tenets that we currently hold for the management of RA were originally proposed over 70 years ago. Russell Cecil in his Textbook of medicine published in 1931 advocated early treatment of RA " ... perhaps the most important factor in prognosis is the application of rational therapy early in the disease." In 2003, we advocate early intervention with disease modifying treatment. Many of the treatments we use today have been developed over 50 years, including gold salts, sulfasalazine, and corticosteroids.

In 2003, methotrexate treatment, early institution of disease modifying antirheumatic drugs (DMARDs), combination DMARDs, and the tumour necrosis factor (TNF) $\alpha$ inhibitors generate the greatest amount of interest for the treatment of RA.

\section{METHOTREXATE}

Despite over 20 years of research and use, there remain problems with methotrexate treatment. Rheumatologists still use doses that are subtherapeutic. In 1990, for 231 patients enrolled in long term prospective studies, the mean dose of methotrexate after 12 months' of treatment was $10.5 \mathrm{mg}$ a week, and at year 4 it was $12 \mathrm{mg}$ a week. ${ }^{1}$ At year 7, the mean dose was up to $14 \mathrm{mg}$ a week. These data from more than a decade ago illustrate that an increase in methotrexate dose may be required for clinical response. It is important to note that, in the initial randomised trials of methotrexate, patients were all started on a dose of $7.5 \mathrm{mg}$ a week, which was increased to $15 \mathrm{mg}$ a week on the basis of clinical response. ${ }^{2}$ Most patients had their dose increased to $15 \mathrm{mg}$ a week. In the only dose-response study of methotrexate for RA, Furst and colleagues ${ }^{4}$ reported that $10 \mathrm{mg} / \mathrm{m}^{2}$ was better than $5 \mathrm{mg} / \mathrm{m}^{2}$, and both doses were better than placebo. The $10 \mathrm{mg} / \mathrm{m}^{2}$ equates to a weekly dose of about 18-19 mg a week. In that study, a higher dose of $20 \mathrm{mg} / \mathrm{mg}^{2}$ was discontinued because significant toxicity was noted. Despite the results from this study, most comparative clinical trials of methotrexate have used a lower dose ( $15 \mathrm{mg}$ a week) as the maximum dose. Only one study (an early study comparing etanercept with methotrexate ${ }^{5}$ ) used the therapeutic dose of $20 \mathrm{mg}$ a week. Patients were started on a dose of $7.5 \mathrm{mg}$ a week, with mandatory dose escalation to 20 $\mathrm{mg}$ a week. Perhaps this dose escalation was a factor in the very positive effects of methotrexate observed in this study and the lack of clinical discrimination between methotrexate and etanercept. In my practice, I start patients on $7.5 \mathrm{mg}$ a week, with dose escalation at week 4 to $15 \mathrm{mg}$ a week, and at week 8 to $20 \mathrm{mg}$ a week. With this rapid dose escalation, the rheumatologist will know within three months whether a patient will respond to methotrexate as a monotherapy.

There has been interest over the last few years in the effects of DMARDs on radiographic progression. All of the newer drugs that have been studied over the past decade, such as leflunomide, infliximab, etanercept, adalimumab, and anakinra, all show a beneficial effect on radiographic progression, with a reduction in joint space narrowing and joint space erosion. Over a decade ago, reductions in joint erosions and joint space narrowing were also observed with methotrexate in multiple comparison studies including methotrexate versus azathioprine $^{6}$ and methotrexate versus auranofin. ${ }^{7}$ In a limited number of patients, healing of erosions has also been observed with methotrexate treatment. In one study, after 28 months of methotrexate treatment, five of 14 patients showed improvement not only in the size of erosions but there was also evidence of erosion healing. ${ }^{8}$ Three of these five patients showed the most substantial clinical response in the study.

More recently there has been exciting information about the beneficial effects of methotrexate on the mortality associated with RA. Krause and colleagues ${ }^{9}$ reported an improvement in overall mortality with methotrexate treatment in their responder versus non-responder population. Choi and colleagues ${ }^{10}$ also reported an improvement in mortality, including cardiovascular events, in patients treated with methotrexate.

\section{EARLY INTERVENTION}

In 2003, there are many treatment approaches to the disease (table 1). There has been a change in the prescribing patterns of United States rheumatologists over the past decade as documented by two studies by Pincus and colleagues. In the first study of seven rheumatology practices, 532 patients with RA were recruited in 1984 and followed up over five years. ${ }^{11}$ In this population, only $15 \%$ of the patients received DMARD treatments within the first two years of disease onset. Over three quarters $(77 \%)$ were receiving low dose prednisone. In 2002, Pincus and colleagues reported a cross sectional study of 232 patients with RA observed from 1998 to 2001. ${ }^{12}$ In this cohort, the first DMARD was initiated within 5.5 months of the first symptoms of RA. The DMARD of choice was methotrexate, being used in $81 \%$ of the patients. Background prednisone was still used in $87 \%$ of the patients. These studies show that, among these rheumatologists, the concept of early intervention was incorporated into their practice.

This concept of early intervention in RA, one that has been advocated for more than a decade, was validated in a Dutch study. ${ }^{13}$ An improvement in joint counts and function was noted in patients with early RA receiving DMARDs compared with anti-inflammatory drugs alone. Additional studies have confirmed that early institution of DMARD treatment has a beneficial effect on clinical outcome and functional status.

\section{COMBINATION DMARDS}

There has been great interest in the use of combination DMARD treatments. Almost all synthetic and biological drugs have been combined with methotrexate as treatment for RA. In a Finnish RA combination study, 195 patients with recent

Abbreviations: DMARD, disease modifying antirheumatic drug; RA, rheumatoid arthritis; TNF, tumour necrosis factor 
Table 1 Approaches to the management of rheumatoid arthritis

- Pyramid approach

- Inverting the pyramid

- Step up and step down

- Sawtooth strategy

- Early intervention

- Single $v$ Combo

- Induction therapy

onset RA (median duration six months) were randomised to receive either a combination of sulfasalazine, methotrexate, hydroxychloroquine, and prednisolone or a single DMARD with or without steroids. ${ }^{14}$ In those patients that received combination therapy, $37 \%$ were in remission after 1 year compared with $18 \%$ on monotherapy. Further examination of this study showed that a delay in institution of treatment was the only significant predictor for remission in patients treated with the single DMARD regimen. ${ }^{15}$ The authors concluded that a delay in the institution of DMARDs of even a few months from the onset of symptoms decreased the ability of a single drug to induce remission in early RA. The same authors also observed that the incidence of cervical spine subluxations was less in patients who received combination therapy than in those who received monotherapy. ${ }^{16}$

Not all studies, however, confirm that earlier aggressive combination therapy is substantially better than monotherapy. In a trial of 82 newly diagnosed patients with untreated RA of less than 12 months' duration, patients were randomised to receive a combination of methotrexate, cyclosporin A, and intra-articular steroids, or sulfasalazine alone. ${ }^{17}$ After 48 weeks of treatment, the numbers of patients who met ACR20\% improvement as well as remission were not significantly different between the two treatment groups.

The concept of induction therapy with biological response modifiers is also generating great interest. In a preliminary report presented at the 2002 ACR meetings, 20 patients were treated within 12 months of onset of symptoms with either methotrexate plus infliximab or methotrexate plus placebo. ${ }^{18}$ After 12 months, the infliximab infusions were stopped. An ACR $50 \%$ response was observed in $77 \%$ of those receiving infliximab plus methotrexate compared with $40 \%$ of those receiving placebo plus methotrexate. Of note, no patient with an ACR $50 \%$ response flared after infliximab treatment had been stopped. This study suggests that early intervention with induction therapy may lead to an impressive clinical effect and the ability to stop the biological agent after 12 months of treatment. Maintenance of effect with methotrexate alone has important pharmacoeconomic consequences. Further studies are needed to confirm these preliminary findings.

\section{OUTCOME AND MORTALITY}

A major question remains on the impact of early intervention with solo or combination DMARDs on outcome and mortality. Scott et al ${ }^{19}$ reported in 1987 that more than half of 112 patients with RA treated over 20 years were either dead or severely disabled by the second decade of disease. In this 20 year study, the authors noted an initial response in the first decade of treatment with traditional treatments including gold, chloroquine, and prednisolone; however, over the second decade, the treatments became less effective. In a more recent study, Gordon and colleagues ${ }^{20}$ reviewed the status of 289 patients followed prospectively for 10 years. Methotrexate was started only in two patients at time point 0 whereas by year 10,36 of the remaining 126 patients were receiving methotrexate treatment. Seventy one patients died over 10 years. There was no significant change in joint tenderness or haemoglobin between year 0 and year 10 . The erythrocyte sedimentation rate declined or stabilised over the decade. Despite the improvement in or plateauing of joint counts and erythrocyte sedimentation rate, there was a worsening of the health assessment questionnaire scores and radiographs over 10 years. Perhaps the increased disability and mortality was related to ineffective older DMARD use rather than earlier intervention with methotrexate and combination treatment. One would hope so!

The mortality associated with RA remains a concern, especially cardiovascular mortality. Gabriel and colleagues at the Mayo Clinic evaluated trends in mortality among patients with RA over four decades. ${ }^{21}$ They reported that the excess mortality associated with RA has not changed over four decades in the Mayo cohort. In a more favourable study from Sweden of 46917 patients identified from 1964 to 1994, a decline in mortality was observed over 20 years. ${ }^{22}$ An excess of coronary artery disease was, however, still present especially in patients with early onset disease.

\section{ANTICYTOKINE TREATMENT}

The last few years have generated great excitement about the use of treatments that down regulate proinflammatory cytokines, including TNF $\alpha$ and interleukin 1. The greatest interest is in those agents that neutralise the activity of TNF $\alpha$, including the monoclonal antibodies, infliximab and adalimumab, and the p75 TNF receptor, etanercept. All of these compounds have been approved for use in combination with methotrexate and two (etanercept and adalimumab) as monotherapy. What is remarkable is the consistency of response with these drugs despite different populations of patients, disease duration, and different investigators. Whether anti-TNF treatment should be used early in the course of disease as monotherapy or as combination therapy will depend on studies in progress.

All of the anti-TNF treatments improve all aspects of disease activity, including clinical status, functional status, and radiographic progression. Whether they will have a positive impact on mortality similar to that seen with methotrexate remains to be determined, but I predict that this will be the case.

\section{SUMMARY OF THE STATUS OF TREATMENT FOR RA IN 2003}

(1) Disability and mortality still occur with RA

(2) No drug used as monotherapy has yet been shown to be better than methotrexate

(3) There is earlier use of DMARD treatment

(4) Early DMARD use is associated with better outcome

(5) Corticosteroids continue to be used as bridge therapy

(6) Combination therapy is effective and should be considered as induction treatment

(7) Anti-TNF treatment is a significant advance

(8) Disease activity remains despite our advances

(9) Clinical studies are more difficult now because of our success; placebo controlled studies need to be re-examined and new designs are needed to further drug development

To conclude, in 2003 have we made significant advances in the treatment of RA? The answer is a resounding yes!

\section{Author's affiliation}

M E Weinblatt, Division of Rheumatology, Immunology and Allergy, Brigham and Women's Hospital, Boston, MA, USA

Correspondence to: $\operatorname{Dr} M E$ Weinblatt, Division of Rheumatology, Immunology and Allergy, Brigham and Women's Hospital, 75 Francis Street, Boston, MA 02115 , USA; mweinblatt@partners.org 


\section{REFERENCES}

1 Weinblatt ME, Maier AL. Longterm experience with low dose weekly methotrexate in rheumatoid arthritis. J Rheumatol Suppl 1990;22:33-8.

2 Weinblatt ME, Coblyn JS, Fox DA, Fraser PA, Holdsworth DE, Glass $\mathrm{DN}$, et al. Efficacy of low-dose methotrexate in rheumatoid arthritis. $\mathrm{N}$ Engl J Med 1985;312:818-22.

3 Williams HJ, Willkens RF, Samuelson CO, Jr., Alarcón GS, Guttadauria $M$, Yarboro $C$, et al. Comparison of low-dose oral pulse methotrexate and placebo in the treatment of rheumatoid arthritis. A controlled clinical trial. Arthritis Rheum 1985;28:721-30.

4 Furst DE, Koehnke R, Burmeister LF, Kohler J, Cargill I. Increasing methotrexate effect with increasing dose in the treatment of resistant rheumatoid arthritis. J Rheumatol 1989;16:313-20.

5 Bathon JM, Martin RW, Fleischmann RM, Tesser JR, Schiff MH, Keystone $E C$, et al. A comparison of etanercept and methotrexate in patients with early rheumatoid arthritis. N Engl J Med 2000;343:1586-93.

6 Jeurissen ME, Boerbooms AM, van de Putte LB, Doesburg WH, Lemmens AM. Influence of methotrexate and azathioprine on radiologic progression in rheumatoid arthritis. A randomized, double-blind study. Ann Intern Med 1991;1 14:999-1004.

7 Weinblatt ME, Polisson R, Blotner SD, Sosman JL, Aliabadi P, Baker N, et al. The effects of drug therapy on radiographic progression of rheumatoid arthritis: results of a 36-week randomized trial comparing methotrexate and auranofin. Arthritis Rheum 1993;36:613-19.

8 Weinblatt ME, Trentham DE, Fraser PA, Holdsworth DE, Falchuk KR, Weissman $B N$, et al. Long-term prospective trial of low-dose methotrexate in rheumatoid arthritis. Arthritis Rheum 1988;31:167-75.

9 Krause D, Schleusser B, Herborn G, Rau R. Response to methotrexate treatment is associated with reduced mortality in patients with severe rheumatoid arthritis. Arthritis Rheum 2000;43:14-21.

10 Choi HK, Hernán MA, Seeger JD, Robins JM, Wolfe F. Methotrexate and mortality in patients with rheumatoid arthritis: a prospective study. Lancet 2002:359:1173-7.

11 Pincus T, Marcum SB, Callahan LF. Longterm drug therapy for rheumatoid arthritis in seven rheumatology private practices. II. Second line drugs and prednisone. J Rheumatol 1992;19:1885-94.

12 Sokka T, Pincus T. Contemporary disease modifying antirheumatic drug (DMARD) in patients with recent onset rheumatoid arthritis in a US private practice: methotrexate as the anchor drug in $90 \%$ and new DMARD in $30 \%$ of patients. J Rheumatol 2002;29:2521-4.
13 Van der Heide A Jacobs JWG, Biilsma JWJ, Heurkens $A H$, van Booma-Frankfort $C$, van der Veen $M$, et al. The effectiveness of early treatment with "second line" antirheumatic drugs. A randomized, controlled trial. Ann Intern Med 1996;124:699-707.

14 Möttönen T, Hannonen P, Leirisalo-Repo M, Nissilä M, Kautiainen H, Korpela $M$, et al. Comparison of combination therapy with single-drug therapy in early rheumatoid arthritis: a randomised trial. Lancet 1999:353:1568-73.

15 Möttönen T, Hannonen P, Korpela M, Nissilä M, Kautiainen $H$, llonen J et al. Delay to institution of therapy and induction of remission using single-drug or combination-disease-modifying antirheumatic drug therapy in early rheumatoid arthritis. Arthritis Rheum 2002;46: 894-8.

16 Jones G, Halberti J, Crotty M, Shanahan EM, Batterham M, Ahern M. The effect of treatment on radiological progression in rheumatoid arthritis: a systematic review of randomized placebo-controlled trials. Rheumatology 2003;42:6-13.

17 Proudman SM, Conachan PG, Richardson C, Griffiths B, Green M McGonagle $D$, et al. Treatment of poor-prognosis early rheumatoid arthritis. A randomized study of treatment with methotrexate, cyclosporin $A$, and intraarticular corticosteroids compared with sulfasalazine alone. Arthritis Rheum 2000;43:1809-19.

18 Quinn MA, Conaghan PG, Greenstein A, Karim Z, Brown C, Emery P. Sustained response in early poor prognosis ra after withdrawal of infliximab therapy [abstract]. Arthritis Rheum 2002:46:3416.

19 Scott DL, Symmons DP, Coulton BL, Popert AJ. Long-term outcome of treating rheumatoid arthritis: results after 20 years. Lancet 1987;1:1108-11.

20 Gordon P, West J, Jones H, Gibson T. A 10 year prospective followup of patients with rheumatoid arthritis 1986-96. J Rheumatol $2001 ; 28: 2409-15$.

21 Gabriel SE, Crowson CS, O'Fallon WM. Mortality in rheumatoid arthritis: Have we made an impact in 4 decades? J Rheumatol 1999;26:2529-33

22 Björnådal L, Baecklund E, Yin L, Granath F, Klareskog L, Ekbom A. Decreasing mortality in patients with rheumatoid arthritis: results from a large population based cohort in Sweden, 1964-95. J Rheumatol 2002;29:906-12 